\title{
PERANCANGAN APLIKASI PENJUALAN, PEMBELIAN PADA TOKO NODENT STORE BERBASIS JAVA NETBEANS DI BUARAN JAKARTA TIMUR
}

\author{
Falya Anastasya ${ }^{1}$, Irwan Agus $^{2}$, Bertha Meyke W. Hutajulu ${ }^{3}$ \\ ${ }_{1,2,3}$ Program Studi Informatika, Universitas Indraprasta PGRI \\ falya.anastasya@gmail.com ${ }^{1}$, irwan.agus08@yahoo.com²
}

\begin{abstract}
Abstrak
Tujuan dari penelitian ini adalah 1. Mengembangkan pengetahuan teknologi terhadap masyarakat dengan cara membiasakan menggunakan sistem komputerisasi dalam kegiatan kerja maupun bisnis agar mempermudah pekerjaan2.Membangun aplikasi penjualan barang agar dapat digunakan pengguna untuk memudahkan memasukan data transaksi. 2.Mempermudah proses pembuatan laporan secara cepat dan efesien sehingga dapat berkembang dengan baik. Metode penelitian Studi lapangan bertempat di Toko Baju Nodent Store Buaran Jakarta Timur pada awal bulan Mei 2019. Penulis melakukan studi lapangan untuk melihat langsung proses penjualan barang. Pada aplikasi ini, bagian admin toko dan bagian gudang dapat bekerja dengan cepat dan akuran, data dapat di up-date dengan mudah dan dengan adanya aplikasi ini diharapkan akan mempermudah kegiatan atau aktivitas pekerjaan dalam mendapatkan ketetapan informasi dengan cepat.

Kata Kunci: Sistem informasi, Penjualan, Java Netbeans.
\end{abstract}

\begin{abstract}
The purpose of this study is 1 . Developing technological knowledge of the community by getting used to using a computerized system in work and business activities in order to facilitate the work. 2. Build a sales application so that users can use it to easily enter transaction data. 2. Simplify the process of making reports quickly and efficiently so that they can develop properly. Research methods Field studies are located at the Nodent Store Store Buaran East Jakarta in early May 2019. The author conducted a field study to see first hand the process of selling goods. In this application, the admin section of the store and the warehouse can work quickly and accurately, the data can be updated easily and with this application it is hoped that it will facilitate the activities or work activities in getting information provision quickly.
\end{abstract}

Keywords: System Information, Sales, Java Netbeans

\section{Pendahuluan}

Perkembangan teknologi saat ini telah sangat berkembang pesat hampir di semua bidang, seperti di bidang pendidikan, pemerintahan, sosial, budaya, dan bidang bisnis. Teknologi diciptakan untuk membantu manusia mempermudah segala sesuatu nya agar menjadi lebih cepat, tepat dan efisien.
Dan persaingan dalam teknologi setiap harinya kian bertambah. Toko Baju Nodent Store merupakan sebuah usaha di bidang penjualan baju atau fashion dikalangan anak muda. Toko Baju Nodent Store membuka usaha nya masih menggunakan cara manual dalam pendataan barang, data transaksi dan pembuatan laporan, semuanya masih di catat di dalam buku. Hal ini tidaklah efisien, 
dikarenakan memakan waktu lebih banyak, dan terkadang sering lupa mencatatkan data transaksi, sehingga data barang masuk dan barang yang terjual tidak sesuai. Hal ini menjadi kendala dalam pembuatan laporan transaksi nya. Permasalahan tersebut sering kali terjadi, sehingga dinilai tidak efektif di dalam pelayanan.

Penerapan teknologi informasi sekarang banyak di gunakan oleh usahawan. Kebutuhan efisiensi waktu dan biaya menyebabkan setiap pelaku usaha merasa perlu menerapkan teknologi informasi dalam lingkungan kerja. Dengan perkembangan teknologi informasi yang luar biasa selama beberapa dekade terakhir, tetapi masih banyak usaha retail atau bahkan suatu perusahaan yang belum menerapkan teknologi informasi agar bisa bersaing di masa yang akan datang, itu sekarang terjadi pada Toko Baju Nodent Store tempat dimana penulis melakukan penelitian. Secara umum teknologi informasi lebih di kenal dengan istilah komputerisasi, yaitu mulai dari input data, proses data dan mendistribusikan data yang di lakukan oleh komputer sehingga berjalan secara otomatis, itu yang akan dilakukan penulis pada Toko Baju Nodent Store untuk meningkatkan efektifitas dan fleksibilitas.

Mengingat pesatnya kemajuan dibidang teknologi informasi dan banyaknya pesaing, maka kegiatan penjualan dan pembelian merupakan bagian yang utama dan penting di Toko Baju Nodent Store. Ada beberapa hal yang dapat menimbulkan kendala pada suatu sistem penjualan dan pembelian secara tunai di Toko Baju Nodent Store yang masih kesulitan mencari data-data, dikarenakan data tersebut masih dalam bentuk arsip.

Toko Baju Nodent Store juga masih menggunakan kalkulator sebagai alat hitung yang terkadang melakukan penghitungan kurang maksimal, diantaranya adalah cenderung akan membuat jenuh, karena data harus dihitung, dicatat dan diproses berulang kali dan banyaknya jumlah data yang harus diolah, kerumitan dalam pemrosesan suatu data, terbatasnya waktu yang diguunakan dalam mengelola data, dan data yang beraneka ragam.
Penulis memberikan batasan-batasan terhadap masalah yang diteliti, antara lain dalam pendataan barang, data transaksi dan pembuatan laporan, semuanya masih di catat di dalam buku. Dari permasalahan tersebut maka dibuatlah sebuah perancangan aplikasi penjualan dan pembelian pada Toko Baju Nodent Store yang dapat mengatasi permasalahan dalam proses pengolahan data yang masih dilakukan secara manual.

\section{Metode Penelitian}

Pada penelitian ini, penulis menggunakan metode penelitian Grounded research. Grounded research adalah suatu metode penelitian yang mendasarkan diri kepada fakta yang menggunakan analisis perbandingan untuk mengandakan generalisasi teori, dan mengembangkan teori dimana pengumpulan data dan analisis data berjalan pada waktu yang bersamaan. Dari definisi diatas, maka terlihat bahwa metode yang digunakan dalam Grounded research adalah reaksi terhadap metode penelitian yang asasnya verifikasi teori. Dalam Grounded Research data merupakan sumber teori,dan teori disebut Grounded Research Karena teori tersebut berdasarkan fakta.

Tujuan Grounded Research adalah untuk melakukan generalisasi empiris, menetapkan konsep-konsep, membuktikan teori dan mengembangkan teori. Metode yang digunakan dalam Grounded Research adalah studi-studi perbandingan berjutuan untuk menentukan seberapa jauh suatu gejala berlaku umum. Penelitian juga bertujuan untuk mempelajari suatu kasus atau gejala dengan membandingkan gejala atau kasus tersebut dengan kasus gejala serupa. Perbandingan demikian akan menjelaskan unsure-unsur baru khas dari kasus yang sedang dipelajari.

\section{Teknik Pengumpulan Data}

Dalam pengumpulan data yang dilakukan oleh penulis mendapatkan data-data serta informasi untuk mendukung penyempurnaan hasil penelitian antara lain:

a. Pengamatan

Pengamatan merupakan suatu cara pengumpulan data dengan mengadakan 
pengamatan langsung terhadap suatu objek dalam suatu periode tertentu dan mengadakan pencatatan secara sistematis tentang hal-hal tertentu yang diamati. Penulis melakukan pengamatan langsung dan mempelajari proses kegiatan pendataan barang pada Toko Baju Nodent Store.

b. Wawancara

Penulis melakukan pengumpulan data dengan diadakannya tanya jawab dengan owner Toko Baju Nodent Store yaitu, Bapak Yondri mengenai pendataan barang masuk, barang keluar, dan laporan barang di toko.

\section{Langkah-Langkah Pengembangan Sistem}

Berikut Tahap-tahap yang dilakukan dalam mengembangkan sistem informasi ini adalah:

a. Analisis

Menganalisis data yang ada pada Toko Baju Nodent Store di Buaran Jakarta Timur, penulis menganalisa data barang masuk, data barang keluar dan laporan.

b. Desain

Melakukan Desain aplikasi Toko Baju Nodent Store di Buaran Jakarta Timur dengan menggunakan Netbeans sebagai perangkat lunak untuk merancang aplikasi pada toko dan layout tampilan yang menarik pada komputer. Didalam desain juga dimasukkan data ke dalam database menggunakan MySQL agar data tersimpan dengan terstuktur.

Dalam merancang sistem database untuk menyimpan data-data yang telah diinput atau dimasukan. Tahapan dalam merancang suatu database adalah:

1) Menganalisa kebutuhan database yang akan dibuat

2) Membuat database

3) Membuat tabel-tabel data

4) Menormalisasikan tabel

5) Menentukan relasi antar tabel

6) Membuat report yang digunakan untuk menampilkan hasil output sebelum dicetak.

c. Pengkodean program

Dalam pembuatan kode program setelah tahapan desain selanjutnya adalah pembuatan kode program yang sesuai dengan desain yang telah dibuat.

d. Pengujian Sistem

Pengujian aplikasi Toko Baju Nodent Store di Buaran Jakarta Timur dengan menggunakan pengujian black box testing. Dalam pengujian ini, yang dilakukan hanya mengamati hasil eksekusi melalui data uji dan memeriksa fungsional dari perangkat lunak. Sehingga dapat digunakan untuk menilai konsistensi program yang digunakan

\section{Hasil dan Pembahasan}

\section{Perancangan Sistem}

Perancangan adalah proses pengembagan spesifikasi baru berdasarkan rekomendasi hasil analisis sistem (Subhan, 2012)

\section{Pengertian Informasi}

Informasi adalah data yang telah diklasifikasikan atau diolah atau diinterprestasikan untuk digunakan dalam proses pengambian keputusan (Sutabri, 2012)

\section{Pengertian Aplikasi}

Aplikasi adalah suatu sub kelas perangkat lunak komputer yang memanfaatka kemampuan computer langsung untuk melakukan suatu upaya yang diinginkan pengguna.

\section{Rancangan Diagram Alir Data}

Rancangan Diagram Alir Data (DAD) merupakan suatu network yang menggambarkan suatu sistem komputerisasi, manualisasi, atau gabungan dari keduanya, yang penggambarannya disusun dalam bentuk kumpulan komponen sistem yang saling berhubungan sesuai dengan aturan mainnya. Berikut adalah rancangan DAD yang penulis usulkan:

a. Diagram Konteks

Diagram ini dibuat untuk menggambarkan sistem secara umum dari keseluruhan sistem yang ada. Diagram Konteks yang diusulkan pada Toko Baju Nodent Store di Buaran Jakarta Timur, yatitu:

1) Konsumen

2) Admin Toko 
3) Supplier

4) Pemilik Toko

Dibawah ini adalah gambar Diagram Konteks yang diusulkan sebagai berikut:

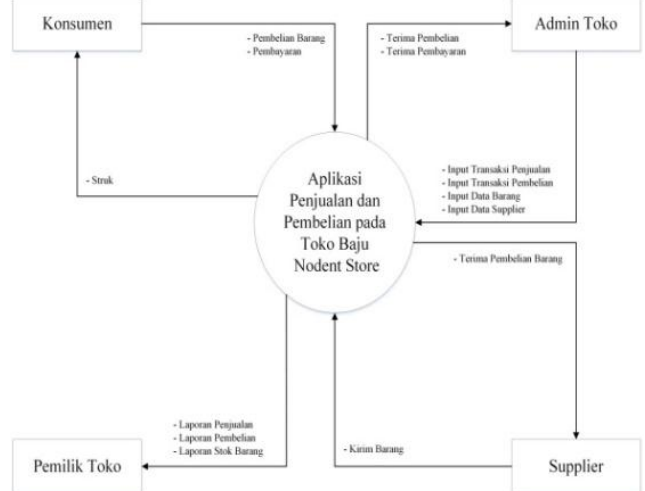

Gambar 1. Diagram Konteks

b. Diagram Nol

Diagram ini dibuat untuk menggambarkantahapan proses yang ada di dalam Diagram Konteks, yang penyebarannya lebih terperinci. Tahapan proses tersebut diantranya adalah:

1) Pendataan Barang dan Pembeian

2) Penjualan

3) Pembelian

4) Laporan

Dibawah ini adalah gambar Diagram Nol yang diusulkan sebagai berikut:

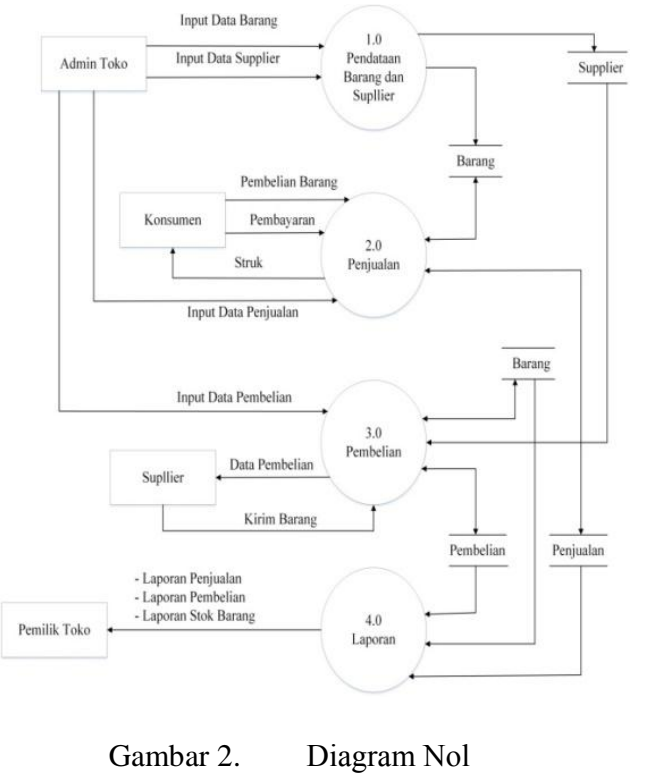

c. Rancangan Entity Relationship Diagram

Entity Relationship (ER) Data model didasarkan pada persepsi terhadap dunia nyata dan tersusun atas kumpulan objekobjek dasar yang disebut entitas dan hubungan antara objek. Entitas adalah suatu atau objek dalam dunia nyata yang dapat dibedakan dari objek lain. Sebagai contoh, masing-masing mahasiswa dan mata kuliah dapat dianggap sebagai entitas.

Entitas digambarkan dalambasis data dengan kumpulan atribut. Misalnya NIM, nama, dan alamat bisa menggambarkan data mahasiswa itu sendiri (Syafaat $\mathrm{H}$, 2012)

Adapun ERD yang penulis usulkan dapat digambarkan sebagai berikut:

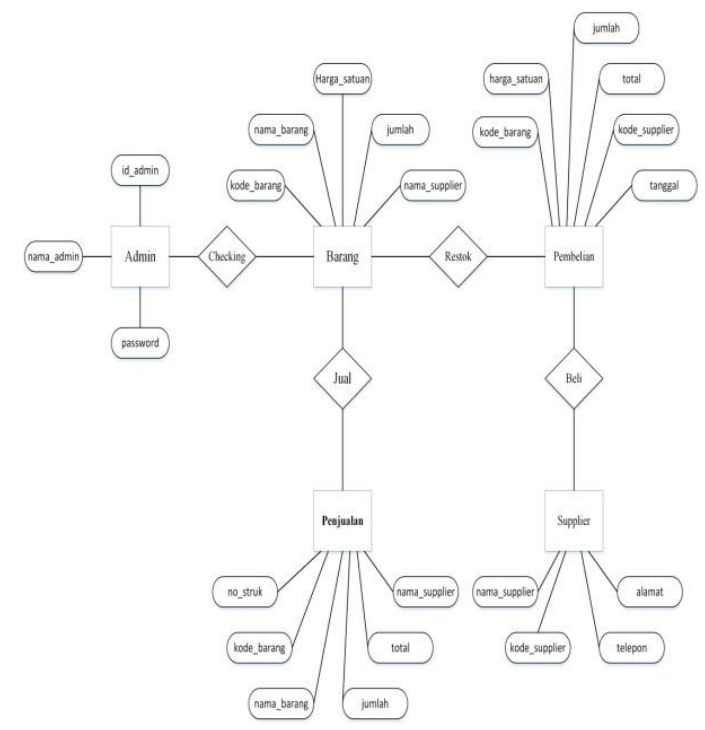

Gambar 3. Entity Relationship Diagram

\section{Tampilan Layar}

Tampilan layar didapatkan dari langkahlangkah pembuatan sistem yang telah dirancang oleh peneliti. Tampilan layar sistem dapat dilihata sebagai berikut:

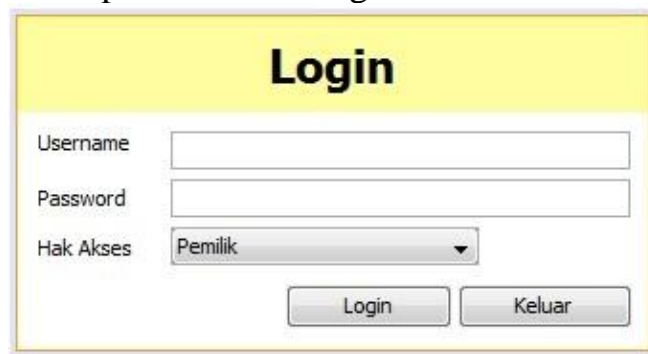

Gambar 4. Form Login

Form login ini terdapat pada awal program. Form login digunakan sebagai kata 
kunci sebelum kita memasukan program utama. Agar tidak sembarangan orang dapat mengakses program ini. Sehingga dalam form menu kerahasiaannya dapat terjaga dengan baik. Apabila pengguna dapat memasukan nama pengguna dan kata sandi pengguna dengan tepat, maka menu utama akan tampil dan program siap untuk dioperasikan.

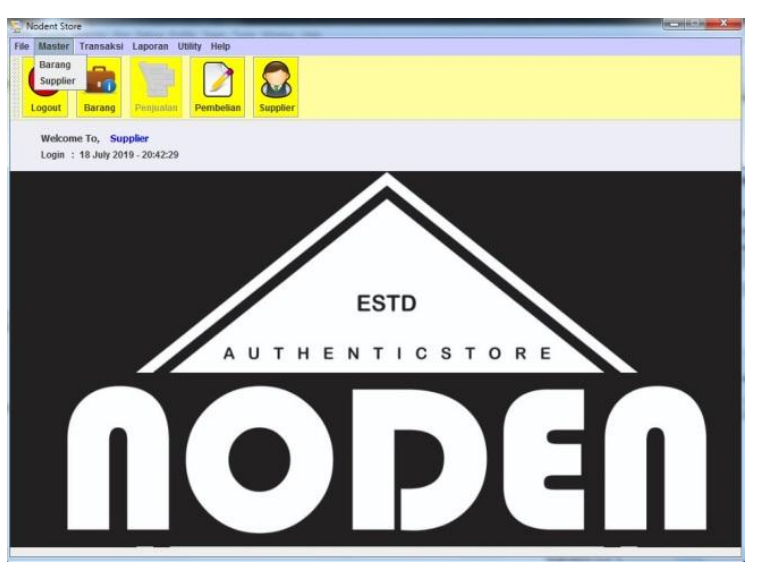

Gambar 5. Rancangan Layar Utama

Rancangan Layar Utama adalah tampilan dasar dari program sistem penjualan dan pembelian barang dimana terdapat beberapa menu/form didalamnya, seperti: Input Transaksi, Input Data, Cetak Laporan dan Keluar. Didalam menu input transaksi terdapat submenu transaksi penjualan dan pembelian, didalam menu input data terdapat submenu data supplier data barang, didalam menu cetak laporan terdapat submenu laporan stok barang, laporan penjualan dan laporan pembelian.

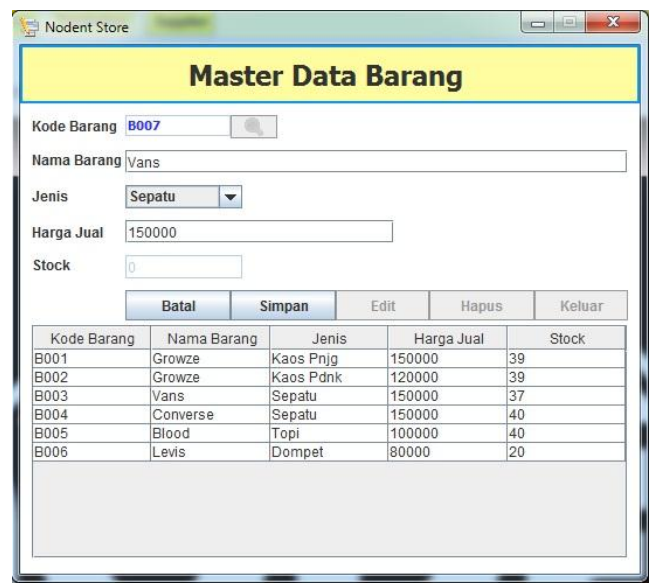

\section{Gambar 6. Form Data Barang}

Form tampilan data barang ini digunakan untuk menginput data barang yang ingin dimasukan kedalam database barang. Form ini digunakan untuk pemanggilan pada form transaksi pembelian dan untuk pemanggilan form stok barang.

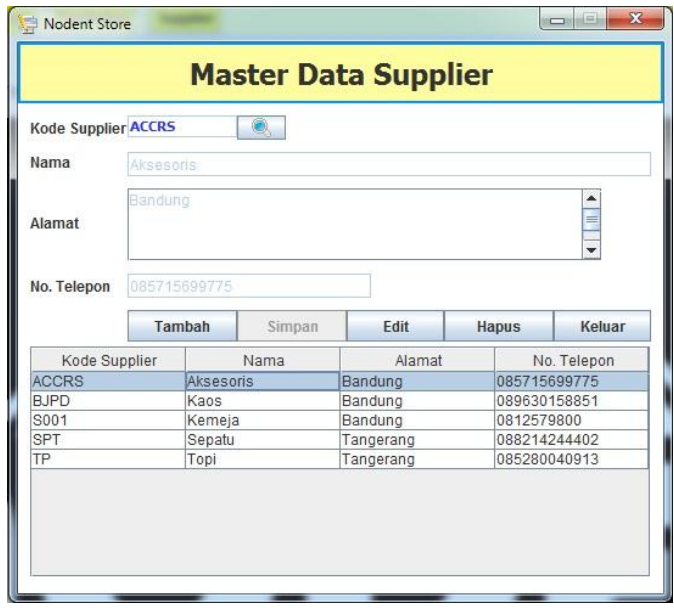

Gambar 7. Form Data Supplier

Form tampilan data supplier ini digunakan untuk menginput data supplier yang bekerjasama dengan Toko Baju Nodent Store. Form ini juga digunakan untuk mengetahui data supplier pada saat ingin membeli barang kepada supplier.

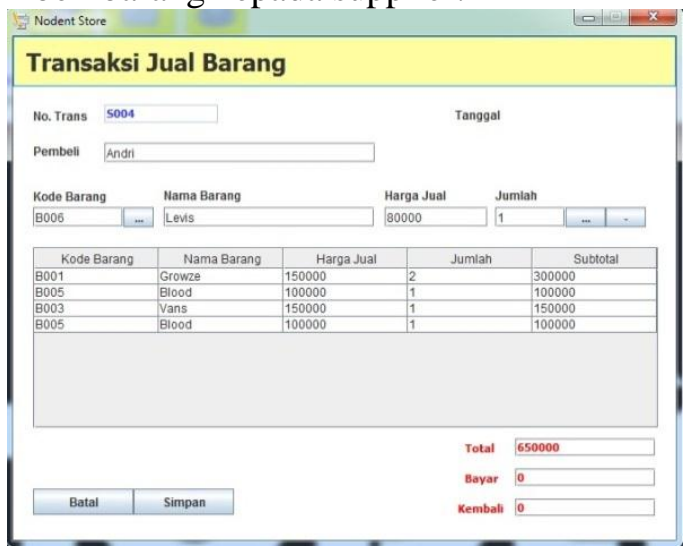

Gambar 8. Form Transaksi Penjualan

Form tampilan transaksi penjualan ini digunakan untuk menginput data barang yang dibeli konsumen. Form ini juga digunakan untuk pemanggilan pada form laporan penjualan. 


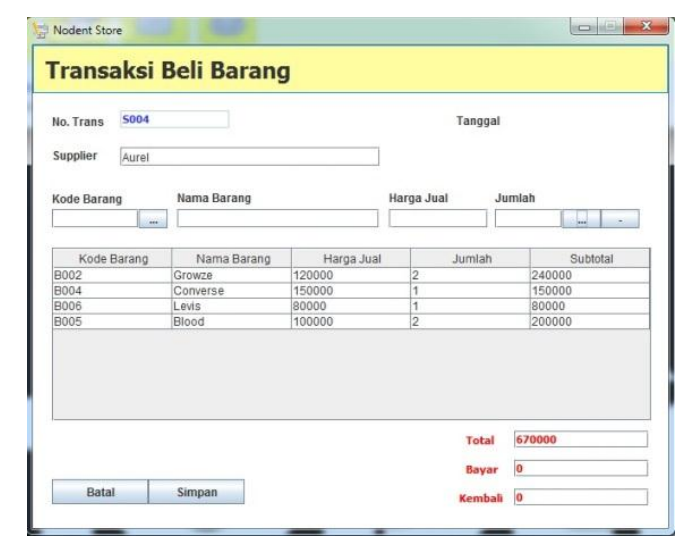

Gambar 9. Form Transaksi Pembelian

Form tampilan transaksi pembelian ini digunakan untuk menginput data barang yang dibeli untuk konsumen. Form ini juga digunakan untuk pemanggilan pada form laporan pembelian.

\section{Simpulan}

Kesimpulan yang penulis dapatkan adalah:

1. Rancanga aplikasi penjualan dan pembelian dapat dikembanganka kembali dalam hal design atau penambahan database sesuai kebutuhan pengolahan datanya.

2. Rancangan apliksai penjualan dan pembelian haruslah didukung oleh sistem yang di siplin dan peraturan yang baik sesuai ketetapan bersama agar dapat berjalan dengan semestinya.

3. Pada proses sistem ini diperlukan penambahan data yang lebih lengkap.

4. Sistem ini diharapkan dapat berkembang dan dimanfaatkan sebagaimana mestinya tanpa adanya penyalah gunaan pada aplikasi.

\section{Daftar Pustaka}

Subhan, M. (2012). Analisa Perancagan Sistem. Jakarta: Lentera Ilmu Cendikia.

Sutabri, T. (2012). Analisis Sistem Informasi. Analisa Sistem Informasi.

Syafaat H, N. (2012). Pemograman Aplikasi Mobile Smartphone dan Tablet PC. Bandung: Informatika Bandung. 